\title{
Impact of Malakit intervention on perceptions, knowledge, attitudes, and practices related to malaria among workers in clandestine gold mines in French Guiana: results of multicentric cross- sectional surveys over time
}

Cécile Longchamps ( $\square$ cecile.longchamps@gmail.com )

Centre d'Investigation Clinique Antilles-Guyane, Inserm 1424, Centre Hospitalier de Cayenne Andrée Rosemon, Cayenne, French Guiana

Muriel Galindo

Centre d'Investigation Clinique Antilles-Guyane, Inserm 1424, Centre Hospitalier de Cayenne Andrée Rosemon, Cayenne, French Guiana

Yann Lambert

Centre d'Investigation Clinique Antilles-Guyane, Inserm 1424, Centre Hospitalier de Cayenne Andrée Rosemon, Cayenne, French Guiana

\section{Alice Sanna}

Centre d'Investigation Clinique Antilles-Guyane, Inserm 1424, Centre Hospitalier de Cayenne Andrée Rosemon, Cayenne, French Guiana

\section{Louise Mutricy}

Centre d'Investigation Clinique Antilles-Guyane, Inserm 1424, Centre Hospitalier de Cayenne Andrée Rosemon, Cayenne, French Guiana

\section{Laure Garancher}

ThelnkLink association, Paris

\section{Antoine Adenis}

Centre d'Investigation Clinique Antilles-Guyane, Inserm 1424, Centre Hospitalier de Cayenne Andrée Rosemon, Cayenne, French Guiana

\section{Mathieu Nacher}

Centre d'Investigation Clinique Antilles-Guyane, Inserm 1424, Centre Hospitalier de Cayenne Andrée Rosemon, Cayenne, French Guiana

\section{Martha Suarez-Mutis}

Parasitic Disease Disease Laboratory, Institute Oswaldo Cruz, Foundation Oswaldo Cruz, Rio de Janeiro Hedley Cairo

National Malaria Programme of Suriname, Paramaribo

Helene Hiwat 
National Malaria Programme of Suriname, Paramaribo

\section{Stephen Vreden}

Foundation for the Advancement of Scientific Research in Suriname, Paramaribo

\section{Maylis Douine}

Centre d'Investigation Clinique Antilles-Guyane, Inserm 1424, Centre Hospitalier de Cayenne Andrée Rosemon, Cayenne, French Guiana

\section{Research Article}

Keywords: mobile population, hard-to-reach population, malaria elimination, knowledge, attitudes, practices, propensity score analysis, Amazon forest

Posted Date: February 24th, 2022

DOI: https://doi.org/10.21203/rs.3.rs-1362837/v1

License: (c) (1) This work is licensed under a Creative Commons Attribution 4.0 International License. Read Full License 


\section{Abstract}

\section{Background}

Clandestine gold miners remain key hosts for malaria in French Guiana (FG) who contribute to imported malaria cases in Suriname and Brazil. The Malakit intervention, implemented in FG borders with Suriname and Brazil, provided gold miners with training on malaria and kits for self-diagnosis and selftreatment. Having shown a likely impact on malaria transmission, Suriname has now implemented it in routine care for cross-border moving populations. However, a decrease in malaria transmission is frequently associated with a decrease in risk perception, knowledge, and good practices regarding malaria. This study aims to describe the evolution of the perceptions, knowledge, attitudes, and practices (KAP) related to malaria among clandestine gold miners between 2015 and 2019 and to estimate the impact of Malakit on the FG/Suriname border.

Method

The primary outcome was the overall KAP score over time and among participants and not participantsin the Malakit intervention. A propensity score matching analysis and an inverse probability of treatment weighing analysis were used to estimate the Average Treatment effect on the Treated and the Average Treatment Effect of Malakit respectively.

Results

Perception and knowledge scores were significantly lower in 2019 compared to 2015 ( -0.27 and -0.23 points respectively, $p<0.001$ ) while attitude and practice scores were higher (respectively +0.16 and +0.47 points, $p<0.001)$. The overall KAP score was significantly higher among participants in Malakit with both propensity score matching $(+0.72$ points, $95 \% \mathrm{IC}[0.29 ; 1.15])$ and inverse probability of treatment weighting analysis $(+0.70$ points, $95 \% \mathrm{IC}[0.34 ; 1.05])$.

\section{Conclusion}

We observed a decrease in perception and knowledge about malaria but an improvement of attitudes and practices as the incidence of malaria decreased. The Malakit intervention seems to have a significant positive impact on the overall KAP related to malaria.

The integration of this strategy into malaria control programs could help to improve the KAP, even in areas where malaria is nearly eliminated, through optimal training and health empowerment.

\section{TRIAL REGISTRATION}

ClinicalTrials.gov registration number : NCT03695770

\section{Background}


In 2020, the worldwide number of malaria cases was estimated at 241 million, causing approximately 627,000 deaths. While malaria strategies led to favorable trends between 2000 and 2015, the main indicators of morbidity and mortality have remained broadly stable since 2015 , with local variations ${ }^{1}$. One of the factors associated with the continuation or resurgence of malaria transmission is human mobility, particularly in cross-border contexts and with the progressive anthropization of natural environments ${ }^{2,3}$. Gold mining areas in the Guiana Shield, a region encompassing French Guiana (FG), Suriname, Guyana and states of Venezuela, Colombia, and Brazil, are often characterized by a high malaria endemicity. Miners can sustain malaria reintroduction in low burden areas because of their frequent cross-border mobility ${ }^{4}$.

FG shares land borders with Brazil (Amapá state) and Suriname. Malaria incidence has decreased in all three territories in the last 15 years ${ }^{5-7}$ but FG is still the only territory in the European Union where autochthonous transmission of malaria is ongoing. The transmission is mainly concentrated in gold mining areas which are usually located more than a day away from the nearest healthcare center ${ }^{8-10}$. Moreover, the delivery of malaria diagnosis and treatment by community health workers at gold mining sites - like in Suriname - are not permitted under French regulations. Therefore, clandestine gold miners in FG are not reached by the health system even if care in health centers is free of charge. In 2016, the World Health Organization (WHO) included Suriname among the 21 countries that could eliminate malaria by $2020^{11}$. However, malaria elimination in Suriname has been challenged by cross-border cases imported from clandestine gold mining areas in FG ${ }^{12}$.

An innovative case management approach, called Malakit, was developed and implemented between 2018 and 2020 resulting from collaboration between Cayenne Hospital (FG), Suriname, and Brazil, to address malaria diagnosis and effective treatment of clandestine gold miners in FG. Ultimately, these efforts aimed to reduce the risk of emergence of resistant Plasmodium falciparum posed by the use of inappropriate treatment by the target population ${ }^{13-17}$. This project consisted in distributing kits containing malaria self-tests and Artemisinin-based combination therapy (ACT) to be used in the gold mining areas in FG, as well as training on malaria and how to correctly self-diagnose and self-treat. From April 2018 to March 2020, 4,766 kits were distributed to 3,733 participants. The estimated coverage of the target population was estimated at $29.7 \%$.

The evaluation of the Malakit intervention showed a significant improvement of self-care behavior: the proportion of gold miners reporting proper treatment with an ACT after a malaria diagnosis in the event of malaria symptoms significantly increased $(\mathrm{OR}=1.8,95 \% \mathrm{Cl}[1.1 ; 3.0])^{18}$. The project has presumably contributed to the reduction of malaria transmission in the region: the incidence and prevalence of malaria decreased significantly in FG and the surrounding territories (Suriname, Amapá), in clandestine gold mines as well as in local inhabitants and so did the number of imported malaria cases from FG to Suriname or Brazil ${ }^{19,20}$. An inversion of the proportion of Plasmodium falciparum and Plasmodium vivax with more than $85 \%$ of $P$. vivax was also found in the gold mining population. This predominance of $P$. vivax is typically found in areas that have reached the control phase of malaria and are entering the 
elimination phase ${ }^{21}$. These results suggest that the elimination of malaria may be feasible in FG by 2025.

Another typical consequence of the decrease in malaria transmission in pre-elimination contexts is a decrease in malaria risk perception, knowledge about the disease, practice of the preventive measures ${ }^{22-}$ 25

It is therefore important to maintain efforts on prevention and access to diagnosis and treatment in the elimination phase if we want to achieve the target set by WHO's Sustainable Development Goals: 'by 2030, end the epidemics of AIDS, tuberculosis, malaria and neglected tropical diseases and combat hepatitis, water-borne diseases and other communicable diseases' 26-29.

Given the positive results of the Malakit project, the Malaria Program in Suriname has implemented the Malakit intervention in routine care for cross-border moving populations. Moreover, a new project is being developed, still in collaboration with Suriname and Brazil, to implement and evaluate a complementary intervention to Malakit that would target $P$. vivax by treating probable hypnozoites carriers (based on epidemiological data and $P$. vivax serology) by 8 -amnioquinoleine.

In this context, to better understand and adapt the information provided to gold miners to achieve malaria elimination in FG and Suriname, we evaluated the evolution of perceptions, knowledge, attitudes, and practices (KAP) related to malaria before and after the Malakit intervention (2015 versus 2019) and for participants in the intervention vs. non-participants.

The objectives were:

- to describe the evolution of the KAP among clandestine gold miners between 2015 and 2019

- to estimate the Average Treatment effect on the Treated (ATT), i.e. the effect of Malakit on the KAP among gold miners included in the intervention between 2018 and 2019

- to estimate the Average Treatment Effect (ATE) of Malakit on the KAP related to malaria, i.e. the potential effect of Malakit on the KAP if all the gold miners passing through resting sites on the FGSuriname border could be included and receive Malakit training.

\section{Methods}

\section{Malakit project}

Malakit is an international and multicentric interventional study with a quasi-experimental design, based on a single group intervention and an independent pre- and post-intervention evaluation survey including participants regardless of their participation or non-participation in the Malakit intervention. The methodology has been previously published ${ }^{14,17}$, and further details are available at www.malakitproject.org. 


\section{Malakit intervention strategy}

The strategy of the intervention is to deliver to persons working on clandestine gold mining sites in FG, a kit (malakit) to enable them to self-diagnose and self-treat when they are in the forest on the gold mining sites in FG. The kits are delivered on resting sites, specific neighborhoods in border towns or small informal settlements located on border rivers where gold miners come to rest, buy supplies or sell gold. Inclusion criteria were being aged 15 years and above and working on clandestine gold mining sites in FG.

This 'malakit' includes three all-species rapid diagnostic tests (RDT), a full artemisinin-based combination therapy (ACT) course, which is the standard treatment, a single dose of primaquine for early clearance of $P$. falciparum gametocytes, and paracetamol. Before receiving a malakit, participants to the intervention received a training on malaria and on the correct use of the kit. As shown in Table 1, the training included information about malaria transmission and symptoms, its diagnosis, its treatment, and its prevention [Supplementary material I].

Community health workers called facilitators were in charge of training and delivering the kits. They belonged to the gold miner community and were fluent or native Portuguese speakers.

Table 1

Content of the participants' malaria training

\section{Malaria training themes \\ Key points}

Transmission

- Vector, mosquito bite

- Parasites, the difference between $P$. vivax and P. falciparum

Symptoms

- Regular malaria symptoms

- Severe symptoms

Diagnosis

- Importance of knowing the cause of the infection before taking a treatment

- How to perform and interpret the self-test

- What to do in case of negative test

Treatment

- Treatment course in case of positive test

- Contraindications

- Adverse events

- Why complete all the treatment (efficacy, resistance)

- What to do in case of severe, persistent or relapse of symptoms

Prevention

- Reminder of the main prevention measures (mosquito nets, repellent on the skin...) 
The training tools were developed through a participatory approach ${ }^{17}$ and included videos, posters, illustrated instructions on the plastic pouch of the malakit and a smartphone application [Supplementary material II].

Implementation evaluation showed that the training was highly interactive ${ }^{13}$. The facilitators adapted the duration of the explanations, the focus on specific messages, and the vocabulary to the participant characteristics (comorbidities, literacy), their understanding during the training and their availability in time $^{132}$. Special attention was given by the facilitators on the comprehension of the correct use of the malakit i.e. self-diagnosis and self-treatment. Information on the transmission by mosquito bite and the ways to prevent it (at least the use of mosquito nets) were systematically mentioned. An impregnated bed net was also distributed to the participants.

Inclusions in the Malakit intervention and follow-up visits were performed between April 2018 and March 2020, with a progressive roll-out in the five inclusion sites located at resting sites for gold miners: two on the FG-Brazil border, two on the FG-Suriname border and one site in Paramaribo, the capital of Suriname [Figure 1].

\section{Pre-post evaluation surveys}

Two cross-sectional surveys, before and after the Malakit intervention assessing KAP and malaria prevalence, were conducted. The gold miners were recruited by snowball sampling method at the resting areas where gold miners entered FG from Brazil (two inclusion sites) and Suriname (four inclusion sites). Inclusion criteria were being 18 years old or more working or accompanying someone on a clandestine gold mining site in $F G$, being out of the forest for less than 7 days, giving written consent.

In this study, we present the data collected along the FG-Suriname border to continuously improve the Malakit intervention now implemented by the Surinamese Malaria Program. The pre-intervention survey took place from January to June 2015, and the post-intervention survey from October to December 2019, in four sites along the Maroni River at the FG-Suriname border [Figure 1].

\section{Title: Inclusion sites for pre/post-intervention surveys and Malakit intervention}

\section{Source: Douine et al., The Lancet Regional Health - Americas, $2021^{16}$}

\section{Data collection}

Once participants' consent was obtained, questionnaires were administered by a mediator, different from the intervention's facilitators [Supplementary material III]. Data were collected on paper or with tablets that transferred anonymized data to a secure online database. The sociodemographic profile of the gold 
miners was assessed by collecting data on gender, age, level of education, country of birth, proficiency in Portuguese, medical coverage in France. Questions regarding the gold mining activity included the time since their first working experience in gold mining and the main activities. Finally, data on the history of malaria, the last episode of malaria, the risk perception and knowledge related to malaria, the attitudes towards malaria treatment and the practice of preventive measures were collected. Two questions about the attitude towards testing and treatment were only asked in the post-intervention survey. The answer modalities of the question about malaria transmission were different in pre and post-intervention survey since a difference was made between "mosquito bite" and "mosquito" in the post-intervention survey while the answer "mosquito" included "mosquito bite" in the pre-intervention survey.

\section{Outcomes}

\section{Primary outcome}

The main outcome of this study was the 12 points KAP score after the intervention [Table 2].

\section{Secondary outcome}

The secondary outcomes of this study were the 9-point KAP score, the 3-point perception score, the 2point and 3-point knowledge scores, the 2-point and 4-point attitude scores and the 2-point practice score [Table 2].

\section{Analysis}

\section{Scores calculation}

The different scores were calculated as shown in Table 2 [Supplementary material IV]. 
Table 2

Scores calculation

\section{SCORES AND DETAILS OF THE SCORES}

BEFORE/AFTER INCLUDED/ NOT

INCLUDED IN MALAKIT

\section{Perception score}

Malaria is a major health problem

Malaria is deadly

Malaria cannot be cured without treatment

Knowledge score

Transmission by mosquitos

Transmission by mosquito bites/mosquitos

$\geq 3$ symptoms of malaria known

Attitude score

Diagnostic test before treatment

No treatment if the test is negative

No treatment interruption until the end

Health professionals' treatments are better than those on the black market

\section{Practice score}

Frequent protection against mosquitos

Last night on gold mining site was under a mosquito net

\section{KAP scores}

3 points

1

1

1

2 points

1

/

1

2 points

/

1

1

/

2 points

1

1

9 points
3 points

1

1

1

3 points

I

2

1

4 points

1

1

1

1

2 points

1

1

12 points

Primary and secondary outcomes are shown in bold.

\section{Statistical analysis}

Frequencies and proportions were calculated for qualitative variables, and median, interquartile range and standard deviation for quantitative variables.

Bivariate analyses were conducted between pre-intervention and post-intervention groups then between the participants included and not included in Malakit in the post-intervention group, using Student's test for quantitative variables, and Chi2 or exact Fisher tests for qualitative variables.

The literature shows strong evidence of the utility and efficacy of using propensity score analysis to estimate the causal effect of public health intervention in the context of quasi-experimental studies to 
reduce selection and causality bias due to lack of randomization ${ }^{30,31}$. The propensity score is the probability of treatment assignment conditional on the measured baseline covariates so that conditional on the true propensity score, treatment status is independent of the measured baseline covariates ${ }^{32}$. Among the different propensity score (PS) analysis methods, Propensity Score Matching (PSM) and Inverse Probability of Treatment Weighting (IPTW) are those recommended to estimate the Average Treatment effect on the Treated (ATT) and the Average Treatment Effect (ATE) respectively ${ }^{33}$. Thus, we performed on the post-intervention group a one-to-one nearest-neighbor PSM analysis to estimate the effect of the Malakit intervention on gold miners who get the intervention and an IPTW analysis to estimate the effect of the Malakit intervention on the overall target population (i.e. all the gold miners frequenting the Malakit distribution sites in Suriname). In our logistic regression model to estimate the propensity score, we included the variables associated with both the inclusion in Malakit and the KAP score or the variables associated only with the KAP score ${ }^{33-35}$ : sex, age, level of education, proficiency in Portuguese, time worked in gold mining, history of malaria, French health insurance coverage.

Participants with missing data for these variables or the variables used to calculate the scores were excluded from the propensity score analysis $(N=26 / 380)$. The covariates balance between participants included and not included in Malakit before and after the propensity score estimation was assessed using the absolute value of the standardized mean difference (SMD) for each covariate. $A|S M D|<0.1$ was considered an adequate balanced and a $|S M D|>0.2$ a serious imbalance ${ }^{36-38}$. Outcome analysis was realized using a linear regression model with a paired t-test for the PSM analysis, and a linear marginal structural model with a t-test for the IPTW analysis. A $5 \%$ significance threshold was fixed. Sensitivity analysis to determine the robustness of our results to hidden biases was performed using the Rosenbaum Sensitivity Test for Wilcoxon Signed Rank P-Value for the PSM analysis ${ }^{39}$ and optimal trimming for IPTW analysis ${ }^{40}$ [Appendix VII].

The effect size of the Student test was calculated using Cohen's d measure. A effect size inferior to 0.2 was considered negligible, minimal if it was between 0.2 and 0.5 and important if it was superior to 0.5 41.

Statistical analysis was performed with RStudio ( ) software version 1.4.1103. The PSM analysis was performed with the Matchlt ${ }^{42}$ and Rbounds ${ }^{43}$ packages and the IPTW analysis with the PSweight ${ }^{44}$ and Survey ${ }^{45}$ packages.

\section{Results}

\section{Participation}

421 participants were included in the pre-intervention survey in 2015 and 380 in the post-intervention survey in 2019. Among the 380 post-survey participants, $30.8 \%(N=117)$ were included in Malakit.

\section{Population characteristics}


Participants included in the pre- and post-survey were mainly male, aged between 30 and 45 years, born in Brazil, working in gold mining for about 10 years [Table 3]. 
Table 3

Pre- and post-intervention surveys' population characteristics

\begin{tabular}{|c|c|c|c|}
\hline & & $\begin{array}{l}\text { Pre-intervention survey } \\
\text { (2015) } \\
(\mathrm{N}=421) \mathrm{N}(\%)\end{array}$ & $\begin{array}{l}\text { Post-intervention survey } \\
\text { (2019) } \\
(\mathrm{N}=380) \mathrm{N}(\%)\end{array}$ \\
\hline \multirow[t]{2}{*}{ Sex } & Female & $124(29.5)$ & $102(26.8)$ \\
\hline & Male & $297(70.6)$ & $278(73.2)$ \\
\hline \multirow[t]{4}{*}{ Age } & Median (IQR) & $37(30-45)$ & $39(31-48)$ \\
\hline & $18-29$ & $91(21.6)$ & $80(21.1)$ \\
\hline & $30-44$ & $214(50.8)$ & $168(44.2)$ \\
\hline & $\geq 45$ & $116(27.6)$ & $132(34.7)$ \\
\hline \multirow[t]{2}{*}{ Country of birth } & Brazil & $395(93.8)$ & $363(95.5)$ \\
\hline & Other & $26(6.2)$ & $17(4.5)$ \\
\hline \multirow[t]{2}{*}{ Education level } & None or primary & $202(48.0)$ & $130(34.3)$ \\
\hline & Secondary or superior & $219(52.0)$ & $249(65.7)$ \\
\hline \multirow[t]{2}{*}{ Portuguese level } & None or low & $13(4.0)$ & $4(1.1)$ \\
\hline & Fluent & $408(96.9)$ & $370(98.9)$ \\
\hline \multirow{2}{*}{$\begin{array}{l}\text { French medical } \\
\text { coverage }\end{array}$} & Yes & $13(3.1)$ & $10(2.6)$ \\
\hline & No & $408(96.9)$ & $370(97.4)$ \\
\hline \multirow{3}{*}{$\begin{array}{l}\text { Time in gold } \\
\text { mining }\end{array}$} & Median (IQR) & $10(5-15)$ & $10(4-18)$ \\
\hline & $\leq 10$ years & $249(59.1)$ & $205(54.1)$ \\
\hline & $>10$ years & $172(40.9)$ & $174(45.9)$ \\
\hline \multirow[t]{6}{*}{ Main occupation } & Gold miner & $206(48.9)$ & $230(60.5)$ \\
\hline & Trader & $92(21.9)$ & $59(15.5)$ \\
\hline & $\begin{array}{l}\text { Cook/Housekeeper/Sex } \\
\text { worker }\end{array}$ & $65(15.4)$ & $55(14.5)$ \\
\hline & & $48(11.4)$ & $23(6.1)$ \\
\hline & driver/Mechanic & $10(2.4)$ & $13(3.4)$ \\
\hline & Other & & \\
\hline
\end{tabular}




\begin{tabular}{|c|c|c|c|}
\hline & & $\begin{array}{l}\text { Pre-intervention survey } \\
\text { (2015) }\end{array}$ & $\begin{array}{l}\text { Post-intervention survey } \\
\text { (2019) }\end{array}$ \\
\hline & & $(\mathrm{N}=421) \mathrm{N}(\%)$ & $(\mathrm{N}=380) \mathrm{N}(\%)$ \\
\hline \multirow[t]{2}{*}{ History of malaria } & Never or $<4$ attacks & $136(32.3)$ & $184(48.8)$ \\
\hline & $>4$ attacks & $285(67.7)$ & $193(51.2)$ \\
\hline
\end{tabular}

\section{Evolution of KAP between 2015 and 2019}

Between 2015 and 2019, the bivariate analysis showed an overall stability of the KAP 9 score $(+0.11$ points, $p=0.213$, Cohen's $d=0.556$ ) but significant decrease for each dimension of the KAP score [Figure 3].

The perception of the risk related to malaria was lower in $2019(-0.27$ points, $p<0.001, d=0.292)$. While in $2015,84.8 \%$ of participants considered malaria to be a major health problem, only $55.3 \%$ cited malaria as one of the top three health problems on the resting sites in 2019 [Supplementary material V].

Similarly, knowledge about the transmission of the disease and its symptoms decreased over time $(-0.23$ points, $p<0.001, d=0.365$ ). Indeed, the mosquito was identified as the cause of malaria by $90.7 \%$ of participants in 2015 by $80.8 \%$ in 2019 , and $85.5 \%$ knew at least 3 symptoms in 2015 versus $72.1 \%$ in 2019.

In contrast, the attitude towards diagnosis and compliance with treatment improved during this period (+ 0.16 points, $p<0.001, d=0.151$ ).

Finally, we observed a better practice of malaria preventive measures $(+0.47$ points, $p<0.001, d=0.298)$, mainly through the use of impregnated mosquito nets.

\section{Effect of Malakit on KAP}

\section{Bivariate analysis}

As shown in Fig. 4, we observed an overall significant improvement in the KAP 12 score for those who participated in Malakit in bivariate analyses $(+0.75$ points, $p<0.001, d=0.479)$ [Figure 4]

This improvement concerns almost all the dimensions of the KAP score: +0.17 points for the perception score $(p=0.010, d=0.292),+0.75$ for the knowledge score $(p=0.011, d=0.285),+0.25$ for the practice score $(p=0.008, d=0.298)$ [Supplementary material Vl].

In bivariate analysis, attitudes towards diagnosis and treatment were not significantly better among Malakit participants compared to non-participants $(+0.24$ points, $p=0.379, d=0.098)$. 


\section{Propensity score estimation and covariates balance}

All the covariates assumed to be potential confounders were imbalanced between the participants and non-participants in Malakit intervention (|SMD|>0.1) in our initial study population [Table 4]. Table 4. Covariates balance between participants and non-participants in Malakit before and after PS estimation

\begin{tabular}{|c|c|c|c|c|c|c|c|c|c|}
\hline \multirow{3}{*}{$\begin{array}{l}\text { BALANCE } \\
\text { Inclusion in } \\
\text { Malakit } \\
\text { Covariates }\end{array}$} & \multicolumn{3}{|c|}{ INITIAL (N = 354) } & \multicolumn{3}{|c|}{$\begin{array}{l}\text { PROPENSITY SCORE } \\
\text { MATCHING }(\mathrm{N}=214)\end{array}$} & \multicolumn{3}{|c|}{$\begin{array}{l}\text { INVERSE PROBABILITY OF } \\
\text { TREATMENT WEIGHTING } \\
(\mathrm{N}=354)\end{array}$} \\
\hline & No & Yes & |SMD| & No & Yes & |SMD| & No & Yes & |SMD| \\
\hline & $\begin{array}{l}(\mathrm{N}= \\
247)\end{array}$ & $\begin{array}{l}(\mathrm{N}= \\
107)\end{array}$ & & $\begin{array}{l}(\mathrm{N}= \\
107)\end{array}$ & $\begin{array}{l}(\mathrm{N}= \\
107)\end{array}$ & & $\begin{array}{l}(\mathrm{N}= \\
247)\end{array}$ & $\begin{array}{l}(\mathrm{N}= \\
107)\end{array}$ & \\
\hline Male (\%) & 78.1 & 67.3 & $0.244^{\star \star}$ & 66.4 & 67.3 & 0.020 & 74.6 & 74.2 & 0.009 \\
\hline Age (years) & 41.2 & 36.9 & $0.403^{* *}$ & 36.6 & 36.9 & 0.035 & 39.9 & 40.0 & 0.012 \\
\hline $\begin{array}{l}\text { None or primary } \\
\text { education level } \\
(\%)\end{array}$ & 39.7 & 25.2 & $0.311^{* \star}$ & 23.4 & 25.2 & 0.043 & 35.3 & 35.1 & 0.005 \\
\hline $\begin{array}{l}\text { Not fluent in } \\
\text { Portuguese (\%) }\end{array}$ & 1.2 & 0.9 & 0.027 & 1.9 & 0.9 & 0.097 & 1.1 & 1.2 & 0.006 \\
\hline $\begin{array}{l}\text { No French health } \\
\text { coverage (\%) }\end{array}$ & 98.0 & 96.3 & $0.102^{\star}$ & 98.1 & 96.3 & 0.099 & 97.4 & 97.3 & 0.005 \\
\hline $\begin{array}{l}\text { Time worked in } \\
\text { gold mining } \\
\text { (years) }\end{array}$ & 13.7 & 10.7 & $0.292^{\star \star}$ & 10.3 & 10.7 & 0.047 & 12.9 & 13.0 & 0.012 \\
\hline $\begin{array}{l}<4 \text { malaria } \\
\text { episodes } \\
\text { experienced (\%) }\end{array}$ & 46.6 & 49.5 & 0.059 & 52.3 & 49.5 & 0.056 & 47.4 & 46.7 & 0.015 \\
\hline
\end{tabular}

*|Standardized mean difference| between 0.1 and $0.2 ; * \star|S M D|>0.2$

As shown in Table 4, after PSM on the nearest neighbor, we obtained a sub-population of 214 participants: 107 included in Malakit, 107 not included in Malakit and all the covariates were balanced. After IPTW, the distribution of measured baseline covariates was similar between participants included and not included in Malakit [Appendix VII].

\section{Average effect of Malakit on participants}

As shown in Table 5, we observed a significant positive overall ATT effect of Malakit since the participants to the intervention had a mean KAP 12 score equal to 9.33 , which is 0.72 points higher than non-participants $(p=0.001, d=0.357)$. 
Table 5

Outcome analysis after PSM among participants and non-participants in Malakit

\begin{tabular}{|lllll|}
\hline $\begin{array}{l}\text { Participant in Malakit } \\
\text { Score }\end{array}$ & $\begin{array}{l}\text { No }(\mathrm{N}=107) \\
\text { Mean }(\mathbf{s d})\end{array}$ & $\begin{array}{l}\text { Yes }(\mathrm{N}=107) \\
\text { Mean }(\mathbf{s d})\end{array}$ & Coefficient [CI95\%] & p-value \\
\hline KAP $12(/ 12)$ & $8.61(1.52)$ & $9.33(1.58)$ & $0.72[0.29 ; 1.15]$ & $0.001^{*}$ \\
\hline Perception $(/ 3)$ & $2.50(0.57)$ & $2.56(0.54)$ & $0.07[-0.08 ; 0.21]$ & 0.380 \\
\hline Knowledge $(/ 3)$ & $1.75(0.96)$ & $2.08(0.81)$ & $0.34[0.08 ; 0.59]$ & $0.010^{*}$ \\
\hline Attitude (/4) & $3.64(0.60)$ & $3.71(0.58)$ & $0.07[-0.07 ; 0.22]$ & 0.439 \\
\hline Practice $(/ 2)$ & $0.72(0.83)$ & $0.97(0.84)$ & $0.25[0.03 ; 0.47]$ & $0.025^{\star}$ \\
\hline
\end{tabular}

${ }^{*} \mathrm{p}<0.05$ using paired t-test

The difference was significant in knowledge $(+0.34$ points, $p=0.010, d=0.287)$ and practice $(+0.25$ points, $p=0.025, d=0.215)$ scores. No significant differences were observed in perception $(p=0.380, d=$ $0.084)$ and attitude $(p=0.439, d=0.081)$ scores.

\section{Potential average effect of Malakit}

As shown in Table 6, the mean of the KAP 12 score among potential participants to Malakit was 9.32, 0.70 higher than the non-participants mean $(p<0.001)$, showing a significant positive overall ATE effect of the intervention. When looking at the specific dimensions, the difference was significant on the knowledge $(+0.021, p=0.018)$ and the practice $(+0.26, p=0.012)$ scores.

Table 6

Outcomes analysis after IPTW among participants and non-participants in Malakit

\begin{tabular}{|c|c|c|c|c|}
\hline Inclusion in Malakit & No $(N=107)$ & Yes $(N=107)$ & Coefficient [Cl95\%] & p-value \\
\hline Score & Mean (sd) & Mean (sd) & & \\
\hline KAP $12(/ 12)$ & $8.62(1.52)$ & $9.32(1.53)$ & $0.70[0.34 ; 1.05]$ & $<0.001^{\star}$ \\
\hline Perception (/3) & $2.41(0.61)$ & $2.52(0.57)$ & $0.10[-0.04 ; 0.25]$ & 0.161 \\
\hline Knowledge (/3) & $1.87(0.94)$ & $2.11(0.80)$ & $0.24[0.04 ; 0.43]$ & $0.018 *$ \\
\hline Attitude (/4) & $3.62(0.64)$ & $3.72(0.55)$ & $0.10[-0.03 ; 0.23]$ & 0.136 \\
\hline Practice (/2) & $0.72(0.83)$ & $0.97(0.83)$ & $0.26[0.06 ; 0.46]$ & $0.012^{\star}$ \\
\hline
\end{tabular}

${ }^{*} \mathrm{p}<0.05$ using t-test

\section{Discussion}

This study shows a significant decrease on perception and knowledge towards malaria between 2015 and 2019 concomitant with the decrease in incidence while improved attitudes and practices. It also 
reveals that participation to the Malakit intervention was associated to improved knowledge and preventive practices related to malaria among gold miners. This information is crucial in the context of malaria elimination in Suriname and French Guiana to avoid malaria resurgence.

\section{Strengths and limitations}

Some limitations should be noted: i) lower statistical power after matching; ii) desirability bias regarding attitudes towards diagnosis and treatment and preventive behavior answers, reduced by the administration of the questionnaire by a mediator familiar with the gold miners' community iii) scores not evaluated in the literature, based on previous studies in the study population ${ }^{46}$.

Our results appear to be robust given their consistency between the PSM and IPTW analysis and the results of the sensitivity analysis [Appendix VIII]. The consistency of our results also suggests that most confounding factors were accounted for when estimating the propensity scores. The use of propensity score analysis, a validated method to evaluate the impact of a public health intervention in a quasiexperimental setting, limits selection and confounding biases ${ }^{30-32}$.

\section{Contrasting evolution of the KAP related to malaria over time}

The evolution of gold miners KAP between 2015 and 2019 shows a significant decrease in the perception of malaria risk and knowledge about the transmission and symptoms of the disease). Another recent study found similar results among gold miners in the FG/Brazil area ${ }^{47}$. This phenomenon is frequently observed in regions achieving malaria control, due to the reduced contact of the population with the disease 22,48 .

In contrast with the literature, we observed a parallel significant improvement of knowledge regarding diagnosis and treatment as well as in preventive behavior such as the use of bednets, even if the practice of preventive measures remains low (practice score mean in 2019: 0.78/2). This paradoxical evolution could be explained by the distribution of mosquito nets by the facilitators at the same time as the delivery of the malakits, as well as by the team's advocacy to ensure that the kits and the nets were not destroyed during military operations on the gold-mining sites.

Another hypothesis to explain the improvement of KAP as a result of Malakit intervention is the dissemination of the information delivered through the facilitators, mainly addressing the behavior in case of symptoms both with the training and the kit delivery, by the participants to the non-participants 18

\section{A positive impact of Malakit on gold miners' KAP}

Malakit seemed to have a significant impact on the overall knowledge, attitudes and practices related to malaria of gold miners. The participation in the intervention increased their KAP 12 score compared to non-participants between 2018 and 2019. Furthermore, if the routine implementation of Malakit by the 
Suriname Malaria Program allowed for the inclusion of all cross-border moving gold miners from FG to Suriname, the KAP 12 score mean would increase in our target population. In our results, the difference is mainly due to the improvement of knowledge about malaria and the practice of preventive measures. Despite a lack of evidence of an actual improvement of the perception and attitude scores, these scores are higher than the knowledge and practice scores, both in participants and non-participants. Moreover, the evaluation of the intervention shows good use of the self-test and treatment of the kit $(71 \%)^{18}$. Thus, as mentioned earlier, there may be a spillover effect of Malakit through the dissemination of information delivered during the training sessions by participants to other people working in gold mines ${ }^{13,15,18}$. A more accurate assessment of the level of exposure to the information delivered in Malakit would be needed to validate this hypothesis and estimate this effect.

\section{Towards malaria elimination: sustaining efforts and engaging communities}

This study and evidence in the literature highlight the importance of remaining vigilant in the context of declining malaria incidence ${ }^{28,49-53}$. Risk perception regarding malaria and behavior changes play a significant role in the control and elimination of malaria since the only reservoir of the disease is human. Therefore, it is essential to raise and maintain awareness and a sustained level of information on malaria in the communities but also among health professionals working with communities $22,23,47,48,54,55$. Mobilizing communities to eliminate malaria requires an understanding of their perceptions of health and disease and working with them to develop innovative educational programs adapted to the sociocultural context ${ }^{56,57}$. Educational tools of Malakit, such as the videos, were designed and tested with the gold miners, were appreciated by the participants and seem to be effective on behavior changes ${ }^{15,17}$, even if there is still room for improvement. Some countries have developed educational programs using traditional arts such as music, theatre, storytelling or movies, to engage hard-to-reach communities through the health care system ${ }^{58-61}$. In our context, songs and music videos may be effective ways to reach out to gold miners, a highly mobile population. Participatory approach and future studies will help developing new tools to engage gold miners in malaria elimination.

However, the community-based approach requires investment in time, financial and human resources. Malaria must therefore remain a priority for countries - even in a context of low transmission - if the aim is to eliminate malaria 49,62 .

\section{Conclusions}

Raising awareness and maintaining communities' participation in malaria programs is a major challenge given the observed decrease in risk perception and knowledge about malaria associated with the decrease in malaria transmission. The community-based and participatory approach of Malakit has proven to be effective in improving overall perceptions, knowledge, attitudes and practices related to diagnosis, treatment, and prevention of malaria among clandestine gold miners. The results of this study will be useful in modifying and improving the training of the participants before their receiving a kit. The 
integration of the Malakit strategy into malaria control programs could help to improve the KAP of targeted communities and its transfer could be considered to other regions with residual malaria in remote areas. Innovative approaches and new tools have to be thought and developed with the communities to maintain their engagement in malaria elimination.

\section{Abbreviations}

\begin{tabular}{ll} 
ACT & Artemisinin-based combination therapy \\
\hline API & Annual Parasite Index \\
\hline ATE & Average Treatment Effect \\
\hline ATT & Average Treatment effect on the Treated \\
\hline FG & French Guiana \\
\hline CI & Confidence interval \\
\hline IPTW & Inverse probability of treatment weighting \\
\hline KAP & Knowledge, attitude, practice \\
\hline OR & Odds ratio \\
\hline PAHO & Pan American Health Organisation \\
\hline P. falciparum, P. vivax & Plasmodium falciparum, Plasmodium vivax \\
\hline PS & Propensity score \\
\hline PSM & Propensity score matching \\
\hline SMD & Standardized mean difference \\
\hline SDG & Sustainable development goals \\
\hline WHO & World Health Organisation
\end{tabular}

\section{Declarations}

\section{Ethics approval and consent to participate}

Each participant gave written consent after clear and appropriate information. Ethics approvals were obtained from the national ethical committee in Suriname, the "Commissie voor Mensgebonden Wetenschappelijk Onderzoek": opinions Number VG10-14 and Number DVG-738).

The project was the subject of a Normal CNIL Declaration on 24 May 2018 (Declaration Number 2188949 v 0) for data analysis according to the General Data Protection Regulation (European Union Regulation 2016/679). 


\section{Consent for publication}

Not applicable

\section{Availability of data and materials}

The datasets used and analysed during the current study are available from the corresponding author on reasonable request.

\section{Competing interests}

The authors declare no conflict of interest.

\section{Funding}

Half of the funding was by the European Regional Development Fund (FEDER) via the Interregional Amazon Cooperation Program (IACP) 2014-2020 ( ${ }^{\circ}$ Presage 3949), supplemented with self-funding from the Hospital of Cayenne, funds from the French Guiana Regional Health Agency and contributions in kind from the Ministry of Health of Suriname from its Global Fund malaria grant (Global Fund to Fight AIDs, Tuberculosis and Malaria) and the Ministry of Health of Brazil.

The funding sources did not have any role in the collection and analysis of the data, nor in the decision to submit the paper for publication.

\section{Authors' contributions}

MD, MG, YL, SV, AA, MN, HH, HC, MSM and AS conceived the study. MD, MG, YL and SV wrote the protocol. MD, MG, YL, LM, LG, SV and HC implemented the study. CL performed the analysis and wrote the first draft. All authors read and approved the final manuscript.

\section{Acknowledgements}

The authors thank sincerely the mediators who collected the data of the pre and post surveys: Audrey Godin, Mylène Cébé, Alan Ribeiro, Florine Corlin; all the Malakit facilitators ; and Mathilde Fekom for her advices on propensity score analysis.

\section{References}


1. World malaria report 2021. https://www.who.int/publications-detail-redirect/9789240040496.

2. Smith, C. \& Whittaker, M. Beyond mobile populations: a critical review of the literature on malaria and population mobility and suggestions for future directions. Malar. J. 13, 307 (2014).

3. Souza, P. F. et al. Spatial spread of malaria and economic frontier expansion in the Brazilian Amazon. PLOS ONE 14, e0217615 (2019).

4. Douine, M. et al. Malaria in Gold Miners in the Guianas and the Amazon: Current Knowledge and Challenges. Curr. Trop. Med. Rep. 7, 37-47 (2020).

5. World Health Organization, G. M. P. World malaria report 2020. 299 https://www.who.int/publications-detail-redirect/9789240015791 (2020).

6. Scully, J. et al. Spatio-Temporal Dynamics of Plasmodium falciparum and Plasmodium vivax in French Guiana: 2005-2019. Int. J. Environ. Res. Public. Health 18, (2021).

7. Secretaria de Vigilância em Saúde - Ministério da Saúde, Brasil. Boletim Epidemiologico - Malaria 2020. https://www.gov.br/saude/ptbr/media/pdf/2020/dezembro/03/boletim_especial_malaria_1dez20_final.pdf (2020).

8. Douine, M. et al. Prevalence of Plasmodium spp. in illegal gold miners in French Guiana in 2015: a hidden but critical malaria reservoir. Malar. J. 15, 315 (2016).

9. Le Tourneau, F. M. Chercheurs d'or - L'orpaillage clandestin en Guyane française - (2020).

10. Douine, M. et al. Illegal gold miners in French Guiana: a neglected population with poor health. BMC Public Health 18, (2017).

11. WHO | The E-2020 initiative of 21 malaria-eliminating countries: 2019 progress report. WHO http://www.who.int/malaria/publications/atoz/e-2020-progress-report-2019/en/.

12. Douine, M. et al. Prevalence of Plasmodium spp. in illegal gold miners in French Guiana in 2015: a hidden but critical malaria reservoir. Malar. J. 15, 315 (2016).

13. Galindo, M. S. et al. Implementation of a Novel Malaria Management Strategy Based on Self-testing and Self-treatment in Remote Areas in the Amazon (Malakit): Confronting a-priori Assumptions With Reality. https://www.researchsquare.com/article/rs-764314/v1 (2021) doi:10.21203/rs.3.rs764314/v1.

14. Douine, M. et al. Malakit: an innovative pilot project to self-diagnose and self-treat malaria among illegal gold miners in the Guiana Shield. Malar. J. 17, 158-158 (2018).

15. Parent, A.-A., Galindo, M. S., Lambert, Y. \& Douine, M. Maliqua: A study within Malakit, a project on malaria and gold miners in French Guiana.

http://medrxiv.org/lookup/doi/10.1101/2021.05.16.21257287 (2021)

doi:10.1101/2021.05.16.21257287.

16. Douine, M. et al. Self-diagnosis and self-treatment of malaria in hard-to-reach and mobile populations of the Amazon: results of Malakit, an international multicentric intervention research project. Lancet Reg. Health - Am. 100047 (2021) doi:10.1016/j.lana.2021.100047. 
17. Galindo, M. S. et al. Setting-up a cross-border action-research project to control malaria in remote areas of the Amazon: describing the birth and milestones of a complex international project (Malakit). Malar. J. 20, 216 (2021).

18. Douine, M. et al. Self-diagnosis and self-treatment of malaria in hard-to-reach and mobile populations of the Amazon: results of Malakit, an international multicentric intervention research project. Lancet Reg. Health - Am. 100047 (2021) doi:10.1016/j.lana.2021.100047.

19. Hiwat, H. et al. Malaria epidemiology in Suriname from 2000 to 2016: trends, opportunities and challenges for elimination. Malar. J. 17, 418 (2018).

20. da Cruz Franco, V. et al. Complex malaria epidemiology in an international border area between Brazil and French Guiana: challenges for elimination. Trop. Med. Health 47, 24 (2019).

21. Lover, A. A., Baird, J. K., Gosling, R. \& Price, R. N. Malaria Elimination: Time to Target All Species. Am. J. Trop. Med. Hyg. 99, 17-23 (2018).

22. Hlongwana, K. W., Mabaso, M. L. H., Kunene, S., Govender, D. \& Maharaj, R. Community knowledge, attitudes and practices (KAP) on malaria in Swaziland: a country earmarked for malaria elimination. Malar. J. 8, 29 (2009).

23. Rajvanshi, H. et al. Assessing community knowledge, attitude and practices to strengthen communication strategy for Malaria Elimination Demonstration Project in Mandla. Malar. J. 20, 354 (2021).

24. DePina, A. J. et al. Knowledge, attitudes and practices about malaria in Cabo Verde: a country in the pre-elimination context. BMC Public Health 19, 850 (2019).

25. Forero, D. A. et al. Knowledge, attitudes and practices of malaria in Colombia. Malar. J. 13, 165 (2014).

26. Mendis, K. et al. From malaria control to eradication: The WHO perspective. Trop. Med. Int. Health TM IH 14, 802-809 (2009).

27. Shretta, R. et al. Malaria Elimination and Eradication. in Major Infectious Diseases (eds. Holmes, K. K., Bertozzi, S., Bloom, B. R. \& Jha, P.) (The International Bank for Reconstruction and Development / The World Bank, 2017).

28. Li, X.-H. et al. Seven decades towards malaria elimination in Yunnan, China. Malar. J. 20, 147 (2021).

29. Shahandeh, K. \& Basseri, H. R. Challenges and the Path Forward on Malaria Elimination Intervention: A Systematic Review. Iran. J. Public Health 48, 1004-1013 (2019).

30. Basu, S., Meghani, A. \& Siddiqi, A. Evaluating the Health Impact of Large-Scale Public Policy Changes: Classical and Novel Approaches. Annu. Rev. Public Health 38, 351-370 (2017).

31. Austin, P. C. An Introduction to Propensity Score Methods for Reducing the Effects of Confounding in Observational Studies. Multivar. Behav. Res. 46, 399-424 (2011).

32. Rosenbaum, P. R. \& Rubin, D. B. The central role of the propensity score in observational studies for causal effects. Biometrika 70, 41-55 (1983). 
33. Austin, P. C. The relative ability of different propensity score methods to balance measured covariates between treated and untreated subjects in observational studies. Med. Decis. Mak. Int. J. Soc. Med. Decis. Mak. 29, 661-677 (2009).

34. VanderWeele, T. J. Principles of confounder selection. Eur. J. Epidemiol. 34, 211-219 (2019).

35. Brookhart, M. A. et al. Variable selection for propensity score models. Am. J. Epidemiol. 163, 11491156 (2006).

36. Rosenbaum, P. R. \& Rubin, D. B. Constructing a Control Group Using Multivariate Matched Sampling Methods That Incorporate the Propensity Score. Am. Stat. 39, 33 (1985).

37. Austin, P. C. Balance diagnostics for comparing the distribution of baseline covariates between treatment groups in propensity-score matched samples. Stat. Med. 28, 3083-3107 (2009).

38. Normand, S. T. et al. Validating recommendations for coronary angiography following acute myocardial infarction in the elderly: a matched analysis using propensity scores. J. Clin. Epidemiol. 54, 387-398 (2001).

39. Rosenbaum, P. R. Sensitivity to Hidden Bias. in Observational Studies (ed. Rosenbaum, P. R.) 105170 (Springer, 2002). doi:10.1007/978-1-4757-3692-2_4.

40. Crump, R. K., Hotz, V. J., Imbens, G. W. \& Mitnik, O. A. Dealing with limited overlap in estimation of average treatment effects. Biometrika 96, 187-199 (2009).

41. Cohen, J. Statistical power analysis for the behavioral sciences. (L. Erlbaum Associates, 1988).

42. Ho, D. E., Imai, K., King, G. \& Stuart, E. A. Matchlt: Nonparametric Preprocessing for Parametric Causal Inference. J. Stat. Softw. 42, (2011).

43. rbounds.pdf.

44. Zhou, T., Tong, G., Li, F., Thomas, L. E. \& Li, F. PSweight: An R Package for Propensity Score Weighting Analysis. ArXiv201008893 Stat (2021).

45. Analysis of Complex Survey Samples.

46. Heemskerk, M. \& Duijves, C. Study on the knowledge, attitudes and practices of malaria and malaria treatment in the small-scale gold mining sector in Suriname.

http://siapsprogram.org/publication/study-on-the-knowledge-attitudes-and-practices-of-malaria-andmalaria-treatment-in-the-small-scale-gold-mining-sector-in-suriname/ (2013).

47. Murta, F. L. G. et al. Perceptions about malaria among Brazilian gold miners in an Amazonian border area: perspectives for malaria elimination strategies. Malar. J. 20, 286 (2021).

48. Al-Adhroey, A. H., Nor, Z. M., Al-Mekhlafi, H. M. \& Mahmud, R. Opportunities and obstacles to the elimination of malaria from Peninsular Malaysia: knowledge, attitudes and practices on malaria among aboriginal and rural communities. Malar. J. 9, 137 (2010).

49. Organisation mondiale de la Santé. Éradication du paludisme: avantages, scénarios futurs et faisabilité : rapport du Groupe consultatif stratégique sur l'éradication du paludisme. (Organisation mondiale de la Santé, 2021). 
50. Maharaj, R., Kissoon, S., Lakan, V. \& Kheswa, N. Rolling back malaria in Africa - challenges and opportunities to winning the elimination battle. South Afr. Med. J. Suid-Afr. Tydskr. Vir Geneeskd. 109, 53-56 (2019).

51. Hii, J., Hustedt, J. \& Bangs, M. J. Residual Malaria Transmission in Select Countries of Asia-Pacific Region: Old Wine in a New Barrel. J. Infect. Dis. 223, S111-S142 (2021).

52. Cohen, J. M. 'Remarkable solutions to impossible problems': lessons for malaria from the eradication of smallpox. Malar. J. 18, 323 (2019).

53. Guo-Ding, Z. \& Jun, C. [Progress and challenges of global malaria elimination]. Zhongguo Xue Xi Chong Bing Fang Zhi Za Zhi Chin. J. Schistosomiasis Control 31, 19-22 (2019).

54. Lu, G. et al. Malaria training for community health workers in the setting of elimination: a qualitative study from China. Malar. J. 17, 95 (2018).

55. Govere, J., Durrheim, D., la Grange, K., Mabuza, A. \& Booman, M. Community knowledge and perceptions about malaria and practices influencing malaria control in Mpumalanga Province, South Africa. South Afr. Med. J. Suid-Afr. Tydskr. Vir Geneeskd. 90, 611-616 (2000).

56. Baltzell, K., Harvard, K., Hanley, M., Gosling, R. \& Chen, I. What is community engagement and how can it drive malaria elimination? Case studies and stakeholder interviews. Malar. J. 18, 245 (2019).

57. Awasthi, K. R., Jancey, J., Clements, A. C. A. \& Leavy, J. E. Community engagement approaches for malaria prevention, control and elimination: a scoping review protocol. BMJ Open 11, e049812 (2021).

58. Lim, R. et al. Drama as a community engagement strategy for malaria in rural Cambodia. Wellcome Open Res. 2, 95 (2017).

59. Atkinson, J.-A. M. et al. Community participation for malaria elimination in Tafea Province, Vanuatu: Part I. Maintaining motivation for prevention practices in the context of disappearing disease. Malar. J. 9, 93 (2010).

60. Ean, M. et al. Theory of change: Drama and arts-based community engagement for malaria research and elimination in Cambodia. Wellcome Open Res. 6, 46 (2021).

61. Manana, P. N. et al. 'Maskandi experience': exploring the use of a cultural song for community engagement in preparation for a pilot Sterile Insect Technique release programme for malaria vector control in KwaZulu-Natal Province, South Africa 2019. Malar. J. 20, 204 (2021).

62. Dhiman, S. Are malaria elimination efforts on right track? An analysis of gains achieved and challenges ahead. Infect. Dis. Poverty 8, 14 (2019).

\section{Figures}




\section{Atlantic Ocean}

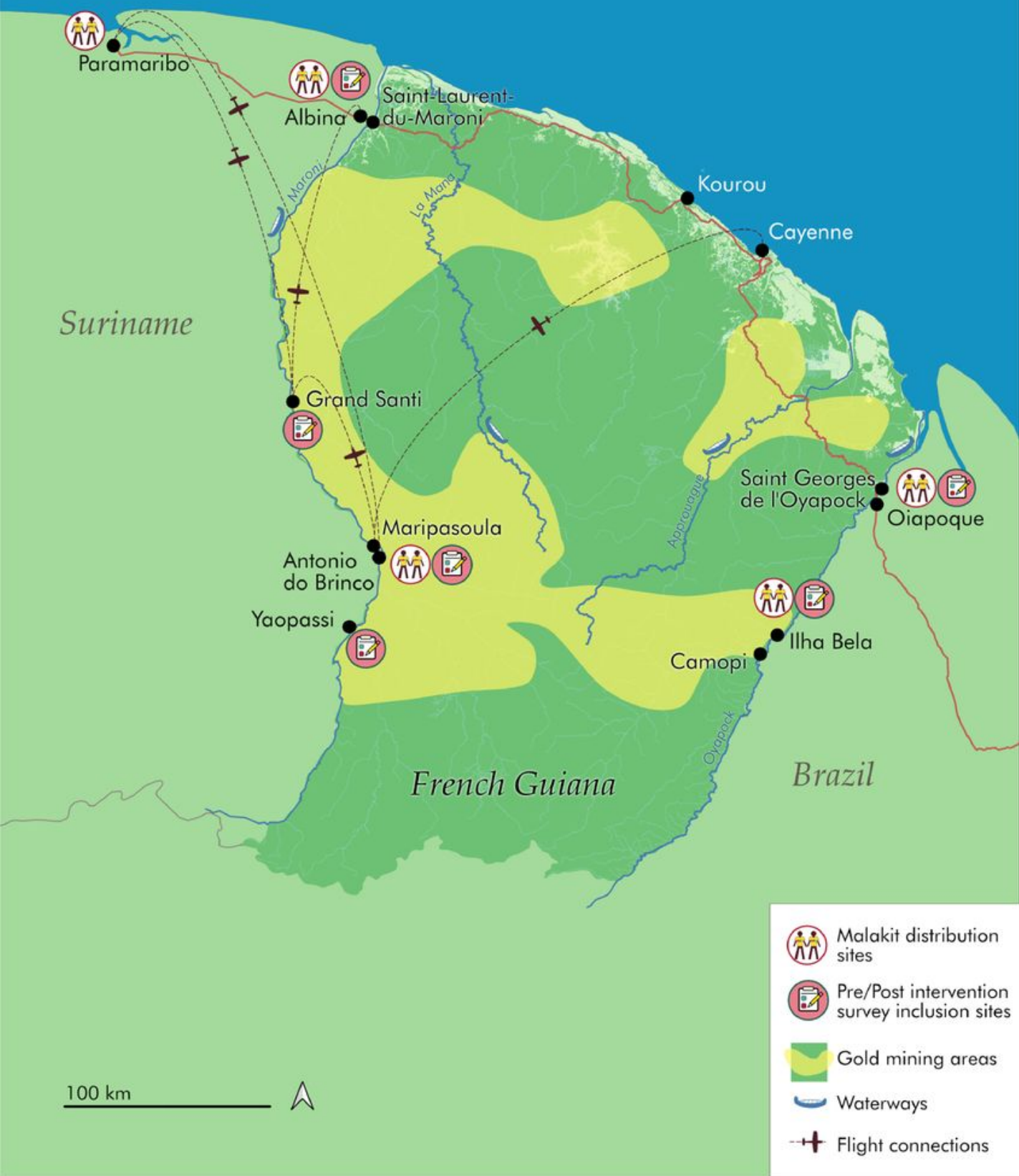

Figure 1

Inclusion sites for pre/post-intervention surveys and Malakit intervention

Source: Douine et al., The Lancet Regional Health - Americas, $2021^{16}$ 


\section{Image not available with this version}

Figure 2

This image is not available with this version.

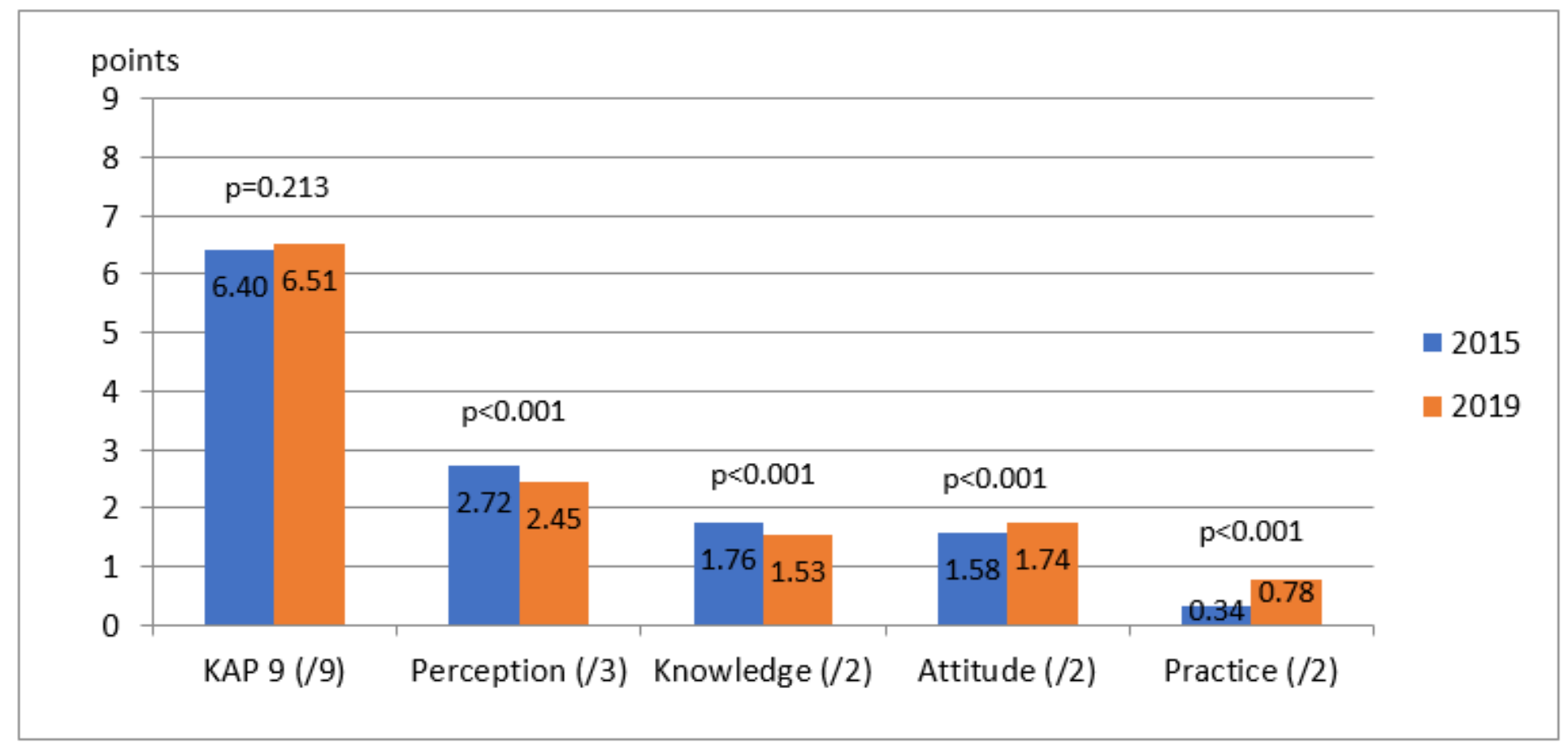

Figure 3

Evolution of the KAP scores before $(\mathrm{N}=421)$ and after $(\mathrm{N}=380)$ the intervention. 


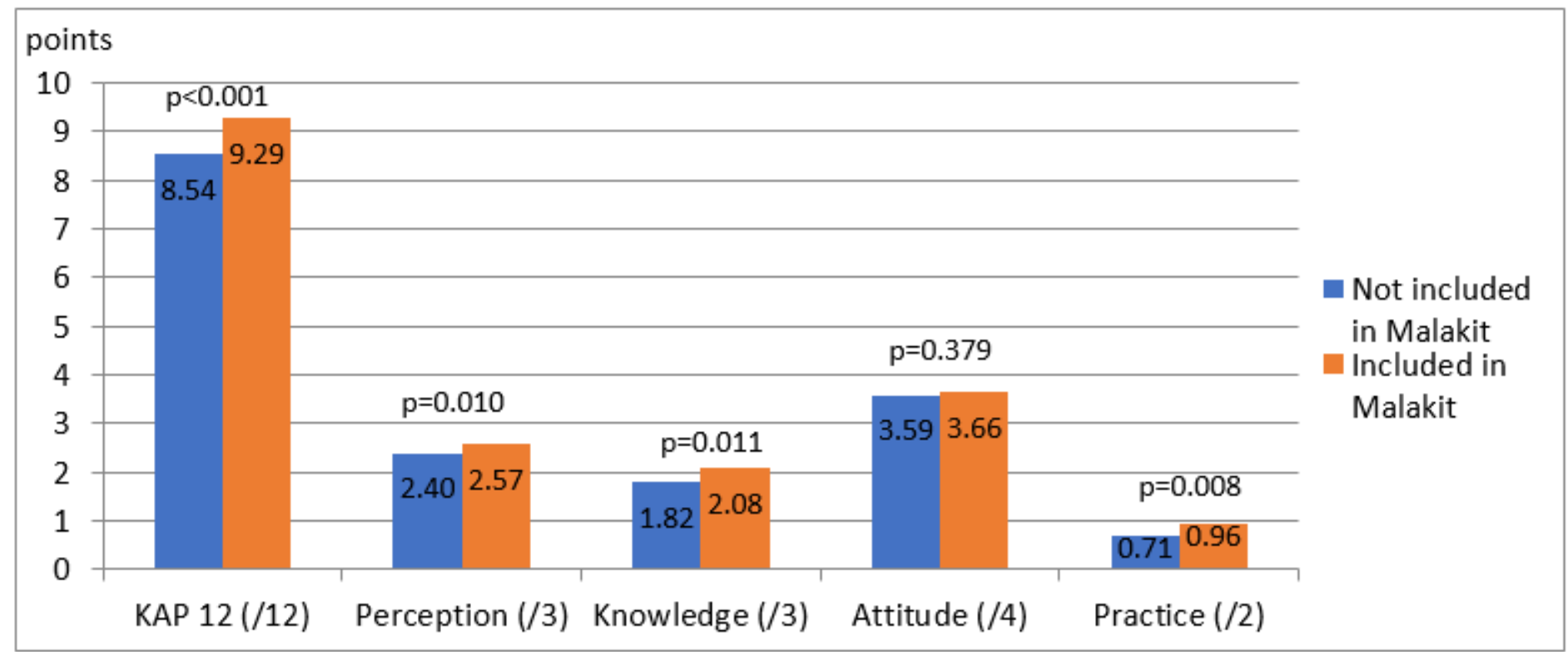

\section{Figure 4}

Bivariate analysis of KAP among Malakit participants $(\mathrm{N}=107)$ and non-participants $(\mathrm{N}=247)$

\section{Supplementary Files}

This is a list of supplementary files associated with this preprint. Click to download.

- Supplementarymateriall.docx

- Supplementarymaterialll.docx

- SupplementarymateriallII.docx

- SupplementarymaterialIV.docx

- SupplementarymaterialV.docx

- SupplementarymaterialVI.docx

- SupplementarymaterialVII.docx 